\title{
Pulsed Current-Voltage-Induced Perturbations of a Premixed Propane/Air Flame
}

\author{
Jacob. B. Schmidt ${ }^{1}$ and Biswa. N. Ganguly ${ }^{2}$ \\ ${ }^{1}$ Spectral Energies, LLC, 5100 Springfield Street Suite 301, Dayton, OH 45431, USA \\ ${ }^{2}$ Air Force Research Laboratory, WPAFB, OH 45433, USA \\ Correspondence should be addressed to Biswa. N. Ganguly, biswa.ganguly@wpafb.af.mil
}

Received 22 November 2010; Accepted 30 March 2011

Academic Editor: Surbamanyam R. Gollahalli

Copyright () 2011 Jacob. B. Schmidt and Biswa. N. Ganguly. This is an open access article distributed under the Creative Commons Attribution License, which permits unrestricted use, distribution, and reproduction in any medium, provided the original work is properly cited.

\begin{abstract}
The effect of millisecond wide sub-breakdown pulsed voltage-current induced flow perturbation has been measured in premixed laminar atmospheric pressure propane/air flame. The flame equivalence ratios were varied from 0.8 to 1.2 with the flow speeds near 1.1 meter/second. Spatio-temporal flame structure changes were observed through collection of $\mathrm{CH}(\mathrm{A}-\mathrm{X})$ and $\mathrm{OH}(\mathrm{A}-\mathrm{X})$ chemiluminescence and simultaneous spontaneous Raman scattering from $\mathrm{N}_{2}$. This optical collection scheme allows us to obtain a strong correlation between the measured gas temperature and the chemiluminescence intensity, verifying that chemiluminescence images provide accurate measurements of flame reaction zone structure modifications. The experimental results suggest that the flame perturbation is caused by ionic wind originating only from the radial positive space-charge distribution in/near the cathode fall. A net momentum transfer acts along the annular space discharge distribution in the reaction zone at or near the cathode fall which modifies the flow field near the cathodic burner head. This radially inward directed body force appears to enhance mixing similar to a swirl induced modification of the flame structure. The flame fluidic response exhibit a strong dependence on the voltage pulse width $\leq 10$ millisecond.
\end{abstract}

\section{Introduction}

The effects of electric fields on flames have been extensively investigated and shown to improve flame stabilization [1-6], change of burnt gas composition [7-9], and enhance flame speed $[5,6,10-14]$ for both premixed and diffusion flames. There are, however, still questions like which effects are mainly responsible for the observed changes; (1) an ionic wind responsible for changing flame shape, (2) a change in the chemical reactions due to ion/electron collisions, and or (3) a conversion of electrical energy into thermal energy. We have investigated flame structure modification of a premixed $\mathrm{C}_{3} \mathrm{H}_{8} /$ air flame that was perturbed by applied voltage, below gas breakdown, with variable pulse-width from 0.5 up to 10 milliseconds (ms). This work is focused on both the onset of turbulence and the behavior of the flame subjected to a pulsed voltage to study the temporal response of the flow field. We report measurements of the effects of electrode locations on the flame structure modifications quantified by phase-locked simultaneous measurements of gas temperature by Raman scattering, time gated 2-D CH (A-X) chemiluminescence images, and also time resolved volume averaged $\mathrm{OH}$ (A-X) chemiluminescence. Vibrational Raman scattering of $\mathrm{N}_{2}$ has been used to determine the temporal variation of the gas temperatures; the spatial and temporal variation of the flame structure was obtained from $\mathrm{CH}(\mathrm{A}-\mathrm{X})$ and $\mathrm{OH}(\mathrm{A}-\mathrm{X})$ chemiluminescence intensities. Also, $\mathrm{CH}^{*}$ chemiluminescence imaging is chosen since its intensity scales with the heat release under certain flame conditions [15]. We have performed calculations of the ionic-windinduced volumetric body force and pressure changes for the experimental conditions presented here, using driftdiffusion equations [16]. We have also investigated the effects of voltage pulse width dependence of the flame perturbation.

The ionic wind hypothesis was described by Lawton and Weinberg [17] to show theoretical maxima for the measured chemi-ion current densities in the flame, and they also calculated ionic wind body-force-induced pressure changes. 
However, in some of the subsequent model calculations of the body force, the effects of electron collision on net momentum transfer by the charge particles in the quasineutral flame gas flow were not included.

A formulation of the body force, derived from the plasma transport equations should include momentum transfer from both electrons and positive ions (negative ions have been neglected due to the polarity dependence of the observed effects) that are produced in a hydrocarbon/air flame by chemi-ionization only (since the applied voltage is below the breakdown voltage). These equations representing ion and electron volumetric forces on a neutral molecule can be represented by (1) and (2), respectively

$$
\begin{aligned}
& \mathbf{f}_{\mathbf{i}}=\mathbf{n}_{\mathbf{i}} \cdot \mathbf{m}_{\mathbf{i}} \cdot \mathbf{v}_{\mathbf{i}} \cdot \mathbf{u}_{\mathbf{i}}, \\
& \mathbf{f}_{\mathrm{e}}=\mathbf{n}_{e} \cdot \mathbf{m}_{e} \cdot \mathbf{v}_{\mathrm{e}} \cdot \mathbf{u}_{\mathrm{e}}
\end{aligned}
$$

where $n$ is the number density, $\mathbf{m}$ is the mass, $\mathbf{v}$ is the collision frequency, and $\mathbf{u}$ is the velocity. Using the drift-diffusion equations and charged particle mobility expressions [18], it is possible to combine these two equations into one equation, as shown in (3), where $\mathbf{e}$ is the fundamental charge, $\mathbf{E}$ is the electric field, $\mathbf{k}_{B}$ is Boltzmann's constant, and $\mathbf{T}_{\mathbf{i}}$ and $\mathbf{T}_{\mathrm{e}}$ are ion and electron temperatures, respectively

$$
\mathbf{f}=\mathbf{e}\left(\mathbf{n}_{\mathbf{i}}-\mathbf{n}_{\mathbf{e}}\right) \cdot \mathbf{E}-\mathbf{k}_{\mathrm{B}} \mathbf{T}_{\mathbf{i}} \nabla \mathbf{n}_{\mathbf{i}}-\mathbf{k}_{\mathrm{B}} \mathbf{T}_{\mathbf{e}} \nabla \mathbf{n}_{\mathbf{e}} .
$$

In most of the flame volume $\mathbf{n}_{\mathbf{i}} \approx \mathbf{n}_{\mathrm{e}}$, so the effects of the body force can only arise from the $\nabla \mathbf{n}$ terms which are usually present near the reaction zone. Using an average number density of positive ions of $3 \times 10^{16} \mathrm{~m}^{-3}$ for a near stoichiometric $\mathrm{C}_{3} \mathrm{H}_{8} /$ air flame and assuming the maximum possible gradient over a distance of $0.2 \mathrm{~mm}$, reaction zone thickness at atmospheric pressure with $2000 \mathrm{~K}$ flame temperature [19], the gradient terms in (3) yield a body force of about $3.5 \mathrm{~N} / \mathrm{m}^{3}$ (negative ion density in the reaction zone is an order of magnitude smaller than the positive ion density [20] so its contribution can be neglected). This is calculated as a volumetric body force along the reaction zone and the effects due to this body force-induced flame flow perturbation should be initiated throughout the entire flame volume. However, our phase resolved pulsed voltageinduced propagation of the flame structure modification measurements or previous measurements of the effects of cathode location [21] do not show measureable effects due to this volumetric body force on the flame.

When a cathode sheath forms at the burner head, the density of the positive ions at the sheath will greatly exceed the density of the electrons. It is possible to rewrite (3) by neglecting the contribution from the electrons. The ionic wind-induced body force on the flame across the cathode sheath is given by the following

$$
\mathbf{f}=\mathbf{E} \cdot \mathbf{e} \cdot \mathbf{n}_{\mathbf{i}} .
$$

Multiplying the volumetric force by the sheath thickness, taken to be 5 electron Debye lengths $\lambda_{D}$, produces an expression for the pressure change across the flame at the burn- er head due to ionic wind effects. Using an average value for the electric field strength of $1 \times 10^{5} \mathrm{~V} / \mathrm{m}$, and the maximum positive ion density of $3 \times 10^{16} \mathrm{~m}^{-3}$, this estimate yields an upper bound of the total body force in the sheath of $\sim 500 \mathrm{~N} / \mathrm{m}^{3}$. The magnitude of these effects on flame structure modifications will be shown to be directly proportional to the applied voltage-induced chemi-ion current and, for a constant current, it is also dependent on the voltage-current pulse width from 0.5 up to $10 \mathrm{~ms}$ (details are described below) for gas flow velocities up to $\sim 2 \mathrm{~m} / \mathrm{sec}$.

\section{Experimental Setup}

The experimental setup used to explore the flame structure perturbation caused by a millisecond-timescale subbreakdown applied voltage pulse is shown in Figure 1, which closely resembles the setup used in previous work $[16,21]$. The setup consists of a premixed $\mathrm{C}_{3} \mathrm{H}_{8}$ /air laminar-flow burner producing an evenly distributed conical flame. The burner used was a commercial atomic absorption type (Perkin-Elmer) with a modified cylindrical (44 $\mathrm{m}$ diameter $\times 50 \mathrm{~mm}$ ) stainless steel head. The premixed gas inlet orifices consisted of five concentric rings of close spaced $0.8 \mathrm{~mm}$ diameter holes. The propane and air were mixed in-line for $1 \mathrm{~m}$ before entering the burner section and then passed through three increasingly smaller gauge wire gauze to homogenize the mixture. Equivalence ratios and flow speeds were accurately measured with a pair of digital thermal mass-flow meters for both fuel and air, accurate to within $0.8 \%$ of the reading. The burner was grounded through a $10 \mathrm{k} \Omega$ current sensing resistor, labeled as $\mathrm{A}$ in Figure 1 . A $1 \mathrm{~mm}$ diameter molybdenum wire was suspended at different heights above the burner surface to serve as an anode for the application of the positive voltage. The thin anode tip temperature is nearly in equilibrium with the gas temperature, and the soot build up is minimal even for fuel rich flames. The pulsed voltage was varied in magnitude (up to $+2.7 \mathrm{kV}$ ) and applied using a $200 \mathrm{k} \Omega$ current limiting ballast resistor to prevent arcing. The current and voltage traces were recorded for each test conditions.

Several groups $[15,22-26]$ have performed both experimental and modeling work to determine if $\mathrm{CH}(\mathrm{A}-\mathrm{X})$ and $\mathrm{OH}$ (A-X) chemiluminescence can be used as a combustion diagnostic tool. It has been generally accepted that chemiluminescence intensity measurements can be used as a marker for flame front structure for a number of applications [27-29]. We have used spectrally resolved flame luminosity measurements, acquired at millisecond time intervals with respect to the applied voltage pulse, to track relative intensity change from $\mathrm{CH}(\mathrm{A}-\mathrm{X})$ and $\mathrm{OH}(\mathrm{A}-\mathrm{X})$ chemiluminescence in the flame to visualize overall flame response. The $\mathrm{CH}$ (A-X) chemiluminescence arise from the reactions $\mathrm{C}_{2} \mathrm{H}+$ $\mathrm{O}_{2} \leftrightarrow \mathrm{CH}^{*}+\mathrm{CO}_{2}$ and $\mathrm{C}_{2} \mathrm{H}+\mathrm{O} \leftrightarrow \mathrm{CH}^{*}+\mathrm{CO}$; OH (A$\mathrm{X})$ chemiluminescence arise from $\mathrm{CH}+\mathrm{O}_{2} \rightarrow \mathrm{OH}^{*}+\mathrm{CO}$ [30]. In this experiment, we have independently correlated chemiluminescence intensities with simultaneous gas temperature measurements by Raman scattering. Images were collected with a Princeton Instruments intensified charge- 


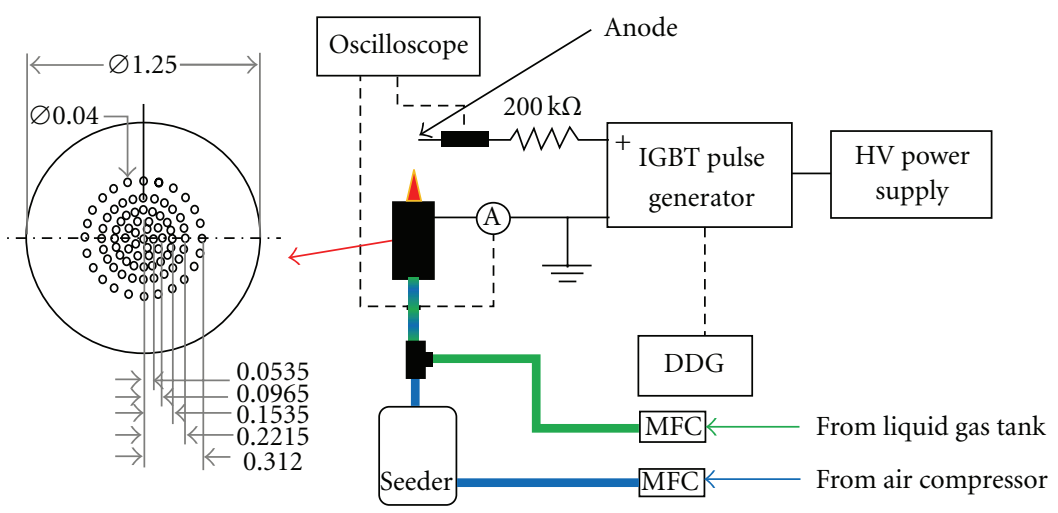

DDG: Digital delay generator

MFC: Mass-flow controller

A: Burner-grounding resistor

FIGURE 1: Schematic for millisecond time-scale applied voltage to a premixed flame. The dimensions are in inch.

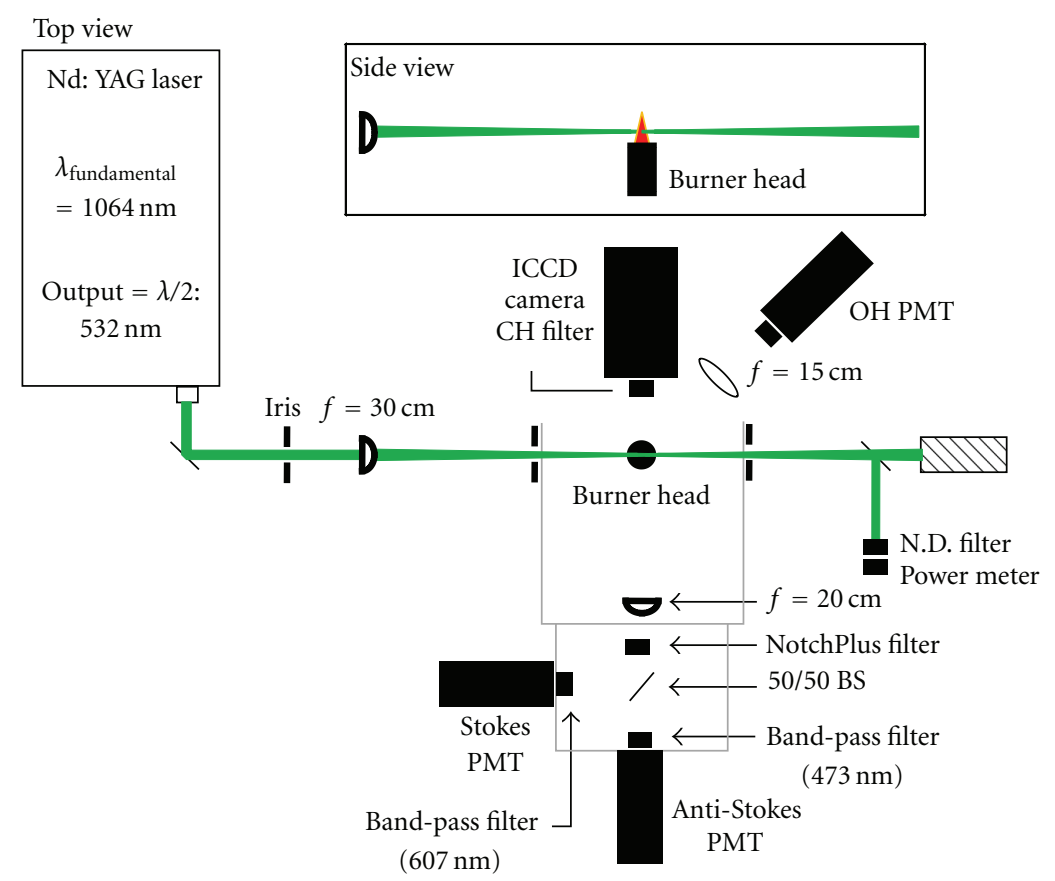

FIgURE 2: Laser diagnostic setup for spontaneous Raman scattering from $\mathrm{N}_{2}$ along with simultaneous measurements of $\mathrm{CH}$ (A-X) chemiluminescence with ICCD images, and flame volume averaged $\mathrm{OH}(\mathrm{A}-\mathrm{X})$ intensity with PMT.

coupled device (ICCD) camera with interchangeable interference filters centered at $308 \mathrm{~nm}$ for $\mathrm{OH}(\mathrm{A}-\mathrm{X})$ and $431 \mathrm{~nm}$ for $\mathrm{CH}(\mathrm{A}-\mathrm{X})$, as shown in Figure 2. The 2-D image of $\mathrm{CH}(\mathrm{A}-\mathrm{X})$ chemiluminescence was acquired with a $200 \mu \mathrm{s}$ exposure time. To increase the signal to noise, individual frames were stacked to form a single image. The $\mathrm{OH}$ chemiluminescence data was also collected by imaging the lower flame volume (closer to the cathodic burner) onto a nongated PMT. This measurement allowed for additional collection of the temporal response of the flame. Due to the line of sight averaged collection of the chemiluminescence image intensity, absolute intensity measurements are not made.
Magnification of flame structure is held constant for all tests performed. All images displayed in Figures 3 to 5 have a spatial scale displayed in the upper-left corner to give spatial size.

Flame structure visualized by the ICCD images was quantified by simultaneous measurement of gas temperature using spontaneous Raman scattering, using the optical collection system shown in Figure 2. A frequency-doubled $532 \mathrm{~nm}$ pulsed $\mathrm{Nd}$ : YAG laser operating at $10 \mathrm{~Hz}$ was focused with a $f=30 \mathrm{~cm}$ lens. This focal spot created a sample volume of $0.5 \mathrm{~mm}^{3}$ and $90^{\circ}$ to this laser beam a $f=20 \mathrm{~cm}$ lens collected this spontaneous emission. After a $50 / 50$ beam 


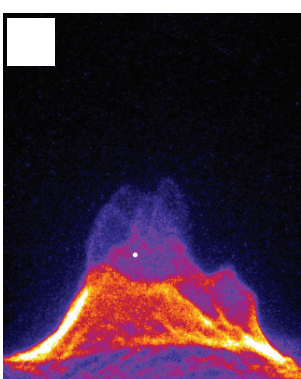

$10 \mathrm{~ms}$

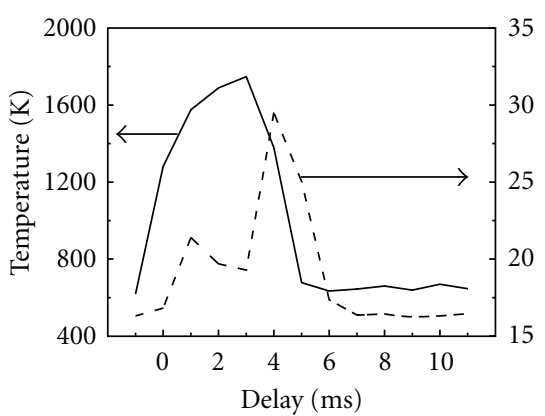

- SASTemp

- - - Img int.

(a)

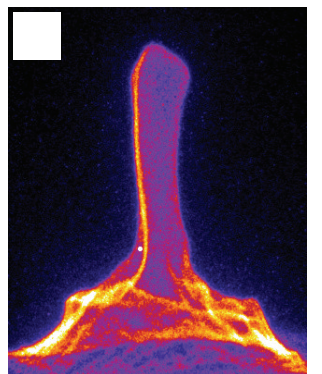

$4 \mathrm{~ms}$

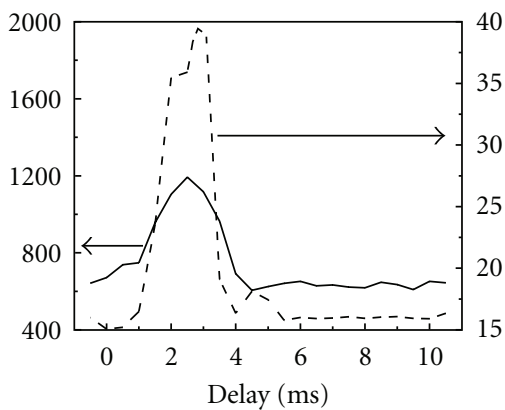

- - - Img int.

(b)

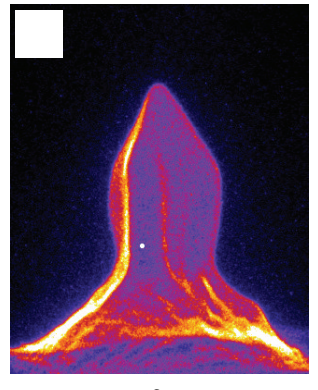

$2 \mathrm{~ms}$

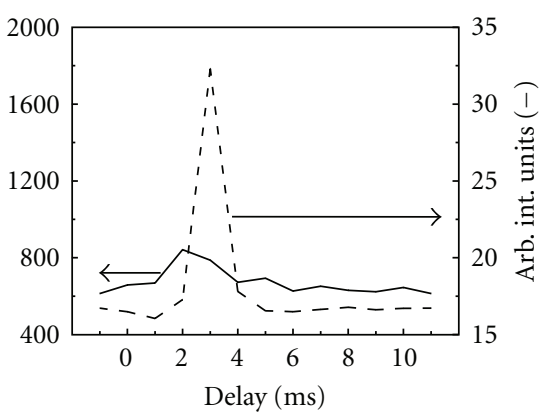

- SASTemp

- - - Img int.

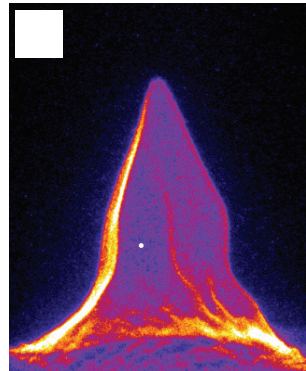

$1 \mathrm{~ms}$

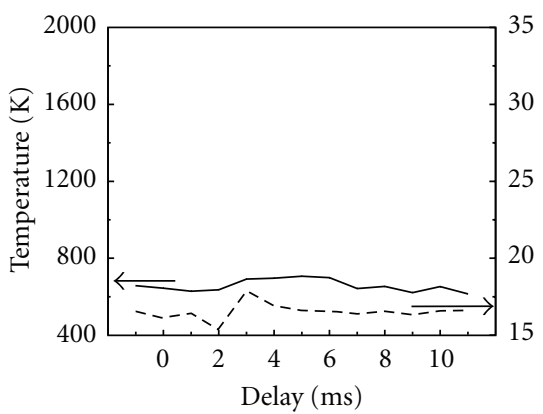

— SASTemp

- - - Img int.

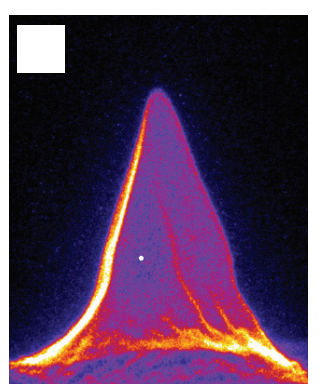

$0.5 \mathrm{~ms}$

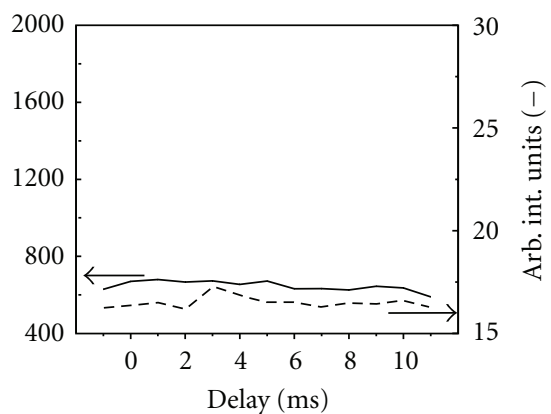

- SASTemp

(c)

(d)

(e)

Figure 3: The effect of $+2.7 \mathrm{kV}$ variable voltage pulse width time, from $10 \mathrm{~ms}$ to $0.5 \mathrm{~ms}$, on flame structure perturbation. Corresponding plots show strong positive correlation between combined Raman temperature and $\mathrm{CH}(\mathrm{A}-\mathrm{X})$ chemiluminescence image signal intensity. The voltage pulse is applied to a $\Phi=1.1$ flame. All images were taken with the same time delay ( $2 \mathrm{~ms})$ from the end of the pulsed voltage. The white box in the upper-left corner of each image is $5 \mathrm{~mm}$ by $5 \mathrm{~mm}$. 


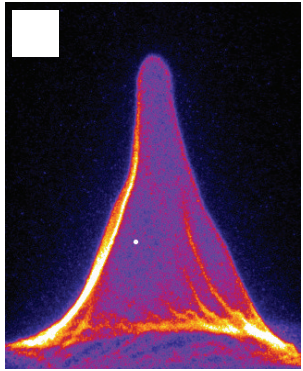

$205 \mu \mathrm{A}(0.87 \mathrm{kV})$

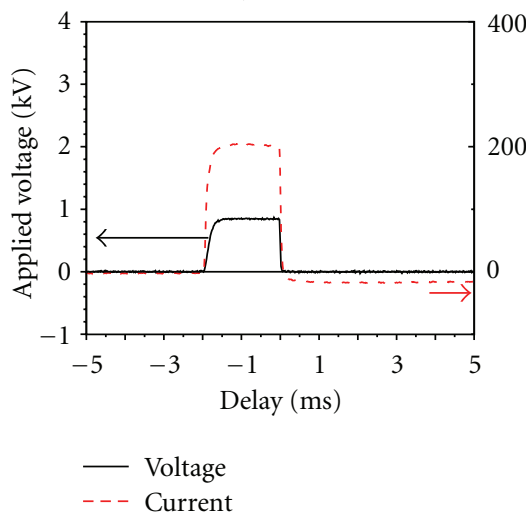

(a)

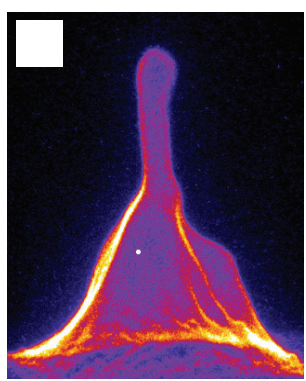

$276 \mu \mathrm{A}(1.8 \mathrm{kV})$

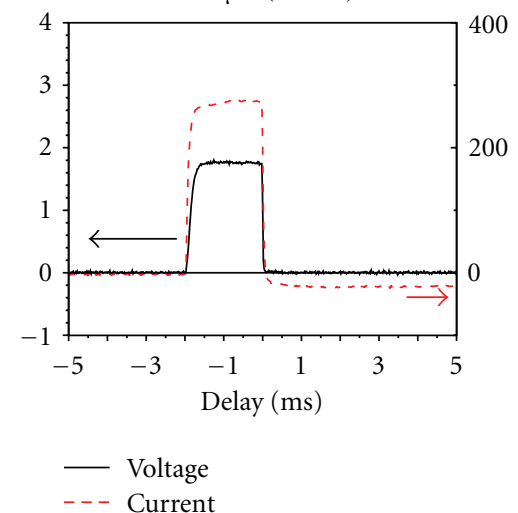

(b)

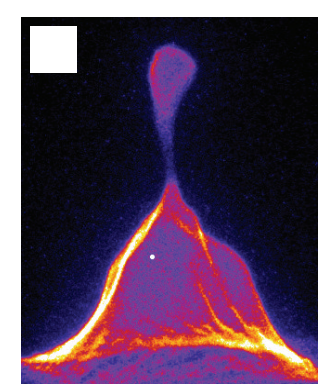

$353 \mu \mathrm{A}(2.76 \mathrm{kV})$

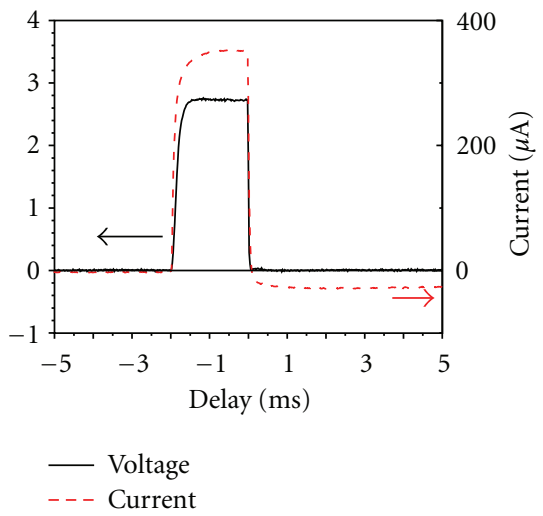

(c)

FIGURE 4: This data sequence details the effect of variable voltage-current on flame perturbation. As the applied voltage is increased from $870 \mathrm{~V}$ (with $205 \mu \mathrm{A}$ current) up to $+2.7 \mathrm{kV}$ (with $353 \mu \mathrm{A}$ current) the level of flame reaction zone perturbation also rises eventually leading to flame pinch off. All images were taken with a $4 \mathrm{~ms}$ wide voltage pulse applied to a $\Phi=1.1$ flame with the same time delay ( $2 \mathrm{~ms}$ ) from the end of the applied voltage. The white box in the upper left corner of each image is $5 \mathrm{~mm}$ by $5 \mathrm{~mm}$.

splitter, the Raman signal was focused on to two gated photon multiplier tubes (PMTs). To simultaneously measure Stokes shifted and anti-Stokes shifted signals at $610 \mathrm{~nm}$ and at $470 \mathrm{~nm}$, respectively, $5 \mathrm{~nm}$ band-pass filters were used with the two gated PMTs. A Notch-Plus filter with in-band optical density of 4.0 was used to eliminate the signal contribution from Mie and Rayleigh scattering. In addition to this filter, baffles were carefully installed to help reduce stray light, and it was possible to operate the gated PMTs at a full gain setting maximizing collection efficiency for the Raman system.

Raman scattering signals from either a Stokes/Stokes or Stokes/anti-Stokes intensity ratio from vibrational levels of the $\mathrm{N}_{2}$ molecule is used to measure gas temperatures [3133]. A temperature calculated from a Stokes/Stokes ratio collected with a single PMT, shown below in (5), does not require relative intensity calibration, but has deficiencies at high temperatures [32]. Calculations relying on Stoke/antiStokes ratio, given below in (6), are better suited for these higher temperature measurements but it needs an intensity calibration to relate the responses of the two separate collection channels. A NIST traceable spectral intensity calibration lamp was used to calibrate the relative response of each PMT channel. With the known spectral intensity output, it was possible to relate the acquired signal to the actual signal produced in this experiment through a calibration constant, $\alpha$, that can account for the differences in collection efficiencies and responses of each PMT. With this calibration, specific signal gain of each PMT could be corrected relative to a known intensity source and to each another, producing an equation for temperature measurement from the Stoke/anti-Stokes intensity ratio. The temperature relations for Stokes/Stokes intensity ratio is given by (5), and Stoke/anti-Stokes intensity ratio is given by (6), where $h$ is Plank's constant, $c_{o}$ is the speed of light in a vacuum, $\widetilde{v}_{k}$ is the Raman shift frequency, $\widetilde{v}_{o}$ is the excitation Raman frequency, $I$ is the respective signal intensity, and $\alpha$ is a calibration constant:

$$
\begin{gathered}
\frac{I_{S @ \text { flame }}}{I_{S @ \text { room }}}=\frac{\left\{1-\exp \left(-h \cdot c_{o} \cdot \tilde{\nu}_{k} / k_{B} \cdot T_{\text {room }}\right)\right\} N_{\text {flame }}}{\left\{1-\exp \left(-h \cdot c_{o} \cdot \widetilde{v}_{k} / k_{B} \cdot T_{\text {flame }}\right)\right\} N_{\text {room }}}, \\
\alpha \cdot \frac{I_{S}}{I_{a S}}=\left(\frac{\widetilde{v}_{o}+\tilde{\nu}_{k}}{\widetilde{v}_{o}-\widetilde{v}_{k}}\right)^{-4} \exp \left(\frac{h \cdot c_{o} \cdot \tilde{\nu}_{k}}{k_{B} \cdot T_{\text {flame }}}\right) .
\end{gathered}
$$

This calibration allowed temperature measurement accuracies of $\pm 80 \mathrm{~K}$ for both intensity ratios between $600 \mathrm{~K}$ and $1500 \mathrm{~K}$. At gas temperatures higher than $1500 \mathrm{~K}$, the absolute accuracy is impacted by the intensity contribution from the vibrational hot bands which can be corrected by iterative data fit as a function of the calculated temperatures. A Stokes/Stokes intensity ratio is relied upon for the lower temperature measurements whereas Stokes/anti-Stokes intensity ratio is used for higher temperatures. All temperature plots will employ this threshold and the resultant plots will be a combination of these two relationships. 


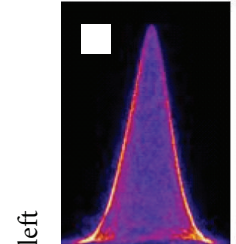

No volt

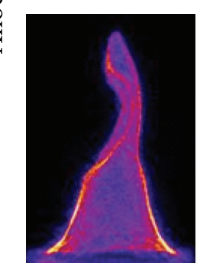

$9 \mathrm{~ms}$

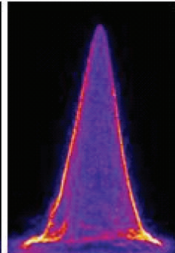

$1 \mathrm{~ms}$

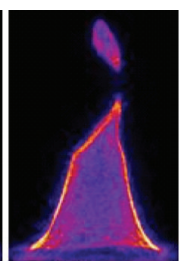

$10 \mathrm{~ms}$

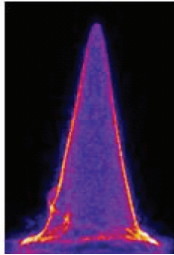

$2 \mathrm{~ms}$

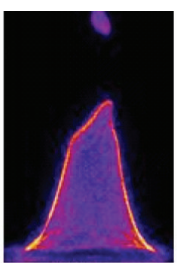

$11 \mathrm{~ms}$

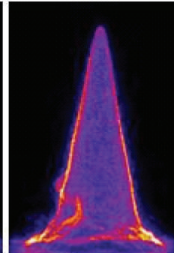

$3 \mathrm{~ms}$

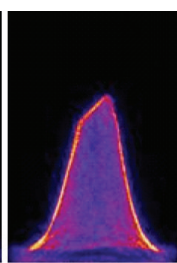

$12 \mathrm{~ms}$

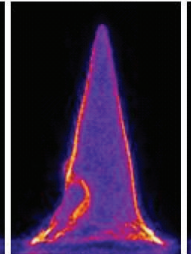

$4 \mathrm{~ms}$

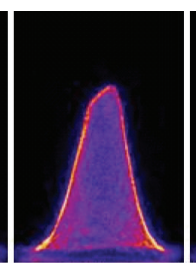

$13 \mathrm{~ms}$

(a)

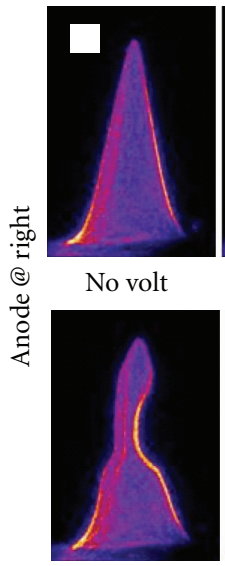

$9 \mathrm{~ms}$

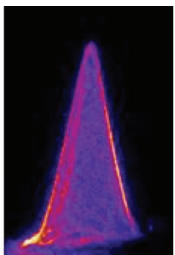

$1 \mathrm{~ms}$

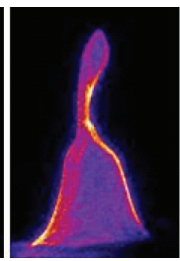

$10 \mathrm{~ms}$

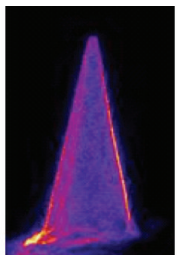

$2 \mathrm{~ms}$

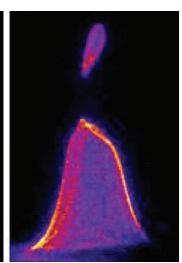

$11 \mathrm{~ms}$

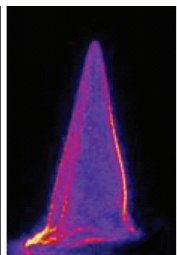

$3 \mathrm{~ms}$

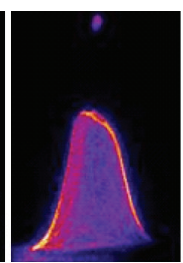

$12 \mathrm{~ms}$

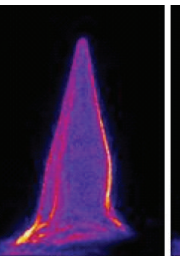

$4 \mathrm{~ms}$

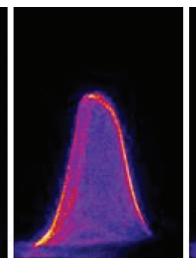

$13 \mathrm{~ms}$

(b)

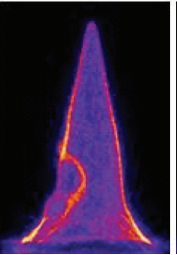

$5 \mathrm{~ms}$

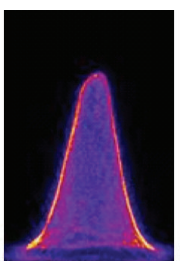

$14 \mathrm{~ms}$

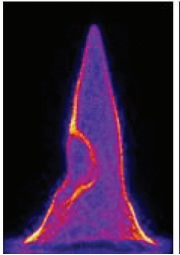

$6 \mathrm{~ms}$

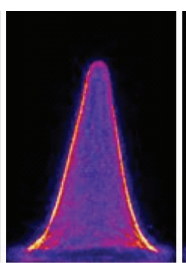

$15 \mathrm{~ms}$

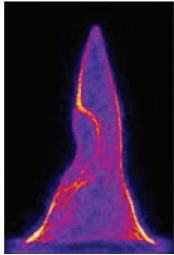

$7 \mathrm{~ms}$

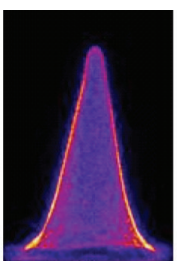

$16 \mathrm{~ms}$
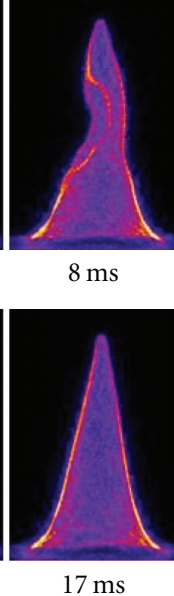

$8 \mathrm{~ms}$

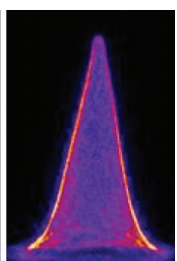

$17 \mathrm{~ms}$

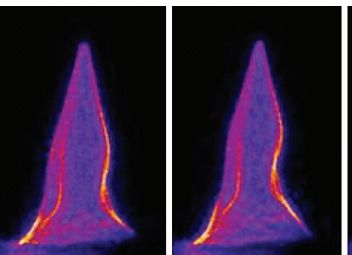

$6 \mathrm{~ms}$

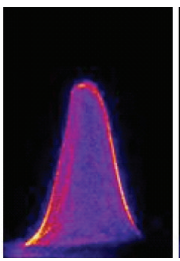

$14 \mathrm{~ms}$

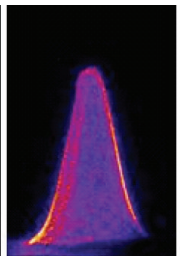

$15 \mathrm{~ms}$

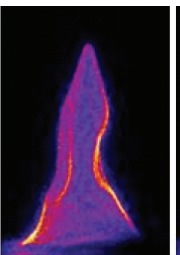

$7 \mathrm{~ms}$

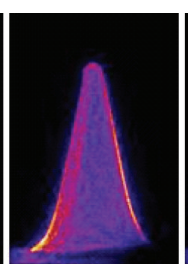

$16 \mathrm{~ms}$

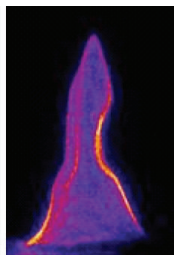

$8 \mathrm{~ms}$

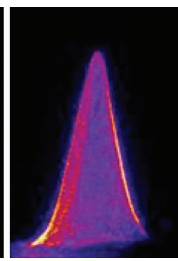

$17 \mathrm{~ms}$

Figure 5: Sequence of $\mathrm{CH}(\mathrm{A}-\mathrm{X})$ chemiluminescence images collected with a gated ICCD camera. This sequence shows that the onset of flame structure modification originates from a specific region at or near the cathode and not in the reaction zone of the entire flame volume. Each set shows a single distortion caused by $+2.7 \mathrm{kV}$ applied voltage across a $3 \mathrm{~mm}$ gap, but differs on the location of the anode. The delay shown is from the end of the $4 \mathrm{~ms}$ applied voltage pulse. The white box in the upper left corner of each "No Volt" image is $5 \mathrm{~mm}$ by $5 \mathrm{~mm}$.

A Stanford Research Systems Digital Delay Generator (DG535) was used as a master clock for the entire setup. Synchronizing the laser pulse, PMT \& ICCD camera gates, and applied voltage at $10 \mathrm{~Hz}$, the DG 535 was used to incrementally move the applied voltage in time relative to the ICCD gate time and the laser pulse enabling repeatable, phase-locked observations of the ms wide pulsed voltageinduced modification of the flame at specified time intervals. Full datasets were collected with equivalence ratio from 0.8 to 1.2 , applied voltage from $0 \mathrm{kV}$ to $+2.7 \mathrm{kV}$, pulse duration from $0.5 \mathrm{~ms}$ up to $10 \mathrm{~ms}$, and also variable time delays from the beginning of the applied voltage pulse at $0 \mathrm{~ms}$ up to $20 \mathrm{~ms}$ for both the $\mathrm{CH}$ and $\mathrm{OH}$ chemiluminescence intensities.

\section{Results and Discussion}

3.1. The Effects of Applied Voltage-Current Pulse Width on Flame Structure Perturbation. It has been suggested [6] that the influence of ionic wind on a flame would exhibit frequency limits based on electric field-induced movement of the ions limited to within the reaction zone only, and the amplitude of the charged species motion is a function of species mobility and electric field strengths. For an atmospheric pressure hydrocarbon/air flame this estimation showed that when applied voltage frequency exceeds $16 \mathrm{kHz}$ ionic wind cannot have any measureable effect. By utilizing kinetic theory and assuming the collisional process between the ions and the neutral molecules as the rate-limiting process, a lower frequency limit was determined to be of the order of $10 \mathrm{~ms}$ for a hydrocarbon flame burning at $1500 \mathrm{~K}$ at atmospheric pressure [6]. Our voltage pulse width dependent flame perturbation measurements, discussed below, support the frequency limit estimates of the ionic wind effects as discussed by Fialkov [6].

An image sequence detailing the behavior of the premixed propane/air flame to $\mathrm{a}+2.7 \mathrm{kV}$ applied voltage pulse 
for voltage pulse width duration from 0.5 up to $10 \mathrm{~ms}$ is shown in Figure 3. It is important to note that this dataset very closely matches previous studies $[16,21]$ performed with DC applied voltage. Examining the effect of upper and lower limits of the applied voltage pulse width, it can be seen that the observed effect for the $10 \mathrm{~ms}$ pulse width causes highly modified flame structure when compared with the same flame condition not subjected to any applied voltage. The flame perturbation produced by the shorter applied voltage-current pulse width, at the same peak voltagecurrent, decreases with the decreasing pulse width, and the flame is almost unperturbed for $0.5 \mathrm{~ms}$ pulse width. All these measurements have been performed with a total electrode gap of $30 \mathrm{~mm}$. Included below in each $\mathrm{CH}(\mathrm{A}-\mathrm{X})$ chemiluminescence image are the corresponding gas temperature and the relative intensity plots of the image, detailing the correlation between the measured gas temperature and the relative intensity change of $\mathrm{CH}(\mathrm{A}-\mathrm{X})$ chemiluminescence. A small white dot in each image locates the region where both Raman scattering and $\mathrm{CH}$ chemiluminescence signal intensity information are collected. This is showing an increase of local chemiluminescence signal which relates to an increase in local gas temperature as measured by the Raman signal. A strong correlation exists between the two independent signal channels verifying that the intensities of the chemiluminescence images are accurate measurements of flame reaction zone structures and they allow conclusive determination of the flame structure modifications. When looking at the differences in $\mathrm{CH}(\mathrm{A}-\mathrm{X})$ images between a $2 \mathrm{~ms}$ and $1 \mathrm{~ms}$ gate width, it is possible to see that the outer edges of the flame have been affected more and show a much more exaggerated "pinch-off" near the base of the flame in the $2 \mathrm{~ms}$ gate width image. For $0.5 \mathrm{~ms}$ or shorter applied voltage pulse width, little to no effects of flame perturbation is observed. These measurements establish upper limits of the induced body force effect of the applied voltage-current at $2 \mathrm{kHz}$. When the effective frequency is increased past this rate, based on the number density of the charged species, the numbers of collisions that can occur are greatly reduced. When the applied voltage-current pulse width is increased to $20 \mathrm{~ms}$, the flame remains fully crushed down (data not shown) but only slightly lower in flame height compared to the $10 \mathrm{~ms}$ gate image. For a $10 \mathrm{~ms}$ pulse width the momentum transfer collisions by the downward propagating positive ions seems to reach its peak value. This experimental result corresponds to the effective lower frequency limit at $100 \mathrm{~Hz}$, in agreement with the estimation given by Fialkov [6].

3.2. Correlation of Minimum Voltage-Current on Flame Perturbation. We have also investigated the applied voltagecurrent limits on flame perturbation. Figure 4 shows these effects for a $4 \mathrm{~ms}$ wide pulse with the applied voltage ranging from $0.87 \mathrm{kV}$ up to $2.76 \mathrm{kV}$ (across a $30 \mathrm{~mm}$ gap) to a flame with $\Phi=1.1$ and total flow speed of $1.1 \mathrm{~m} / \mathrm{s}$. The voltagecurrent plots accompanying these flame images demonstrate a positive correlation between the chemi-ion current and the flame perturbation produced by the ion drift induced body force near the cathode. An increase in applied voltage increases total current flow. Above some minimum current threshold, the strong flame perturbation depends on the total current and it is capable of making a very large-scale change of the flame structure for a relatively small amount of input electrical energy. A small change in the chemiluminescence intensity image on the left in Figure 4 is measured with $200 \mu \mathrm{A}$ current whereas the image on the right shows a very large change at $350 \mu \mathrm{A}$ current.

3.3. The Effect of Anode Locations. We have also studied the effect of anode location on the flame perturbation for a given applied voltage. Figure 5 shows an image sequence detailing the behavior of the premixed propane/air flame to $\mathrm{a}+2.7 \mathrm{kV}$ applied voltage ( $250 \mu \mathrm{A}$ current $)$ with the anode wire placed at the two opposite sides of the flame reaction zone. For both cases, the anode-cathode gap is $3 \mathrm{~mm}$ and the anode is placed at the outer edge of the reaction zone. The top image sequence correspond to the anode (not visible in the images) placed on the left side whereas for the bottom image sequence the anode was placed on the right. The displayed flame image sequences have an equivalence ratio of 0.8 and an overall flow speed of $1.05 \mathrm{~m} / \mathrm{s}$ and they differ only on the location of the anode. By measuring current and voltage it was possible to ensure that both flames encountered the same applied voltage and current. Most notably the image sequence in Figure 5 demonstrates a strong dependence of the flame perturbation on the location of the anode. This dataset emphasizes the point made earlier that the observed flame reaction zone structure distortion originates at or near the base of the flame and not in the entire volume of the flame reaction zones. While the disturbances were seen on opposite sides of the flame, the effects such as propagation speed of the reaction zone structure distortion, overall flame shape, and the onset time of the flame disturbance initiations were very much the same. This indicates that flame response is highly dependent on the direction and path of the applied voltage induced motion of the charge carriers. Additionally, it was noticed that the reaction zone on the opposite side of the flame from the anode moved outward and away from the anode as the disturbance moved through that portion of the flame.

3.4. Ionic Wind-Induced Flame Instability. The nature of the flame flow disturbance is also of interest and it is these flame structures in Figures 3, 4, and 5 that provide additional insight into the nature of the flow perturbation process. Specifically, these images are showing pocket formation and the onset of turbulence (or instability) in an initially unperturbed laminar flame. It is known [18] that turbulent flow results when instabilities in a flow are not sufficiently damped by viscous action and the fluid velocity at each point in the flow exhibits random fluctuations. These fluctuations give rise to the creation of eddies in the flow which can increase the surface area of the reaction zone for a flame, effectively increasing the burning velocity and reducing the flame height. Both of these characteristics are observed in those figures. Because the increase in burning velocity is related to random flow fluctuations, the position of the 


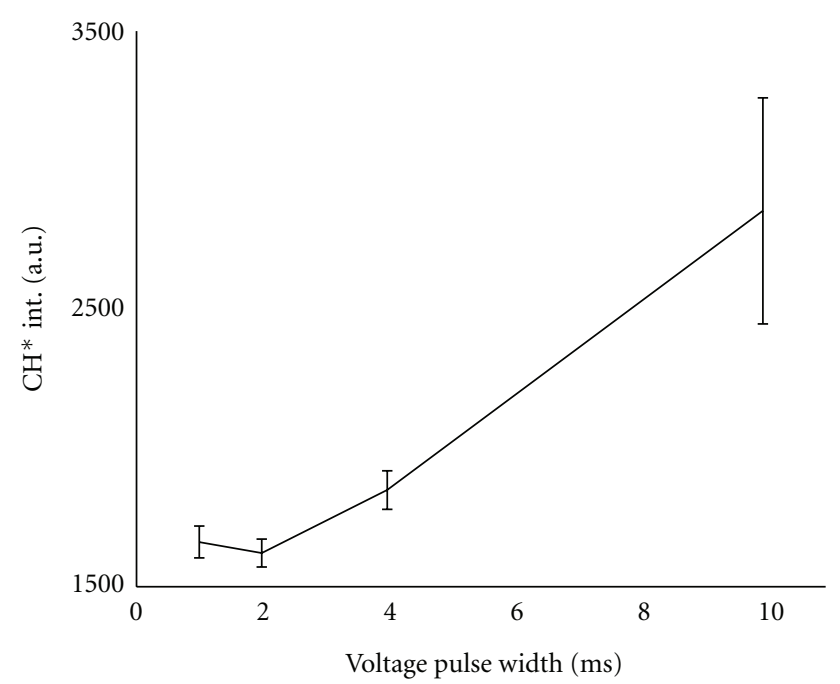

Figure 6: Plot of intensity fluctuations of a reaction zone as a function of the applied voltage pulse width. With $+2.7 \mathrm{kV}$ applied voltage and increasing pulse width, the $\mathrm{CH}$ (A-X) chemiluminescence intensity fluctuation becomes increasingly larger suggesting that reaction zones become more mobile, indicating a transition from laminar flow to turbulence.

reaction zone moves rapidly in space producing a turbulent flame brush, which is thicker than a laminar reaction zone. These multiple reaction zones are shown in the $10 \mathrm{~ms}$ image in Figure 3, which are visible because the image in Figure 3 is produced by averaging eight frames together on the camera chip. The large instabilities cause the reaction zone to become highly mobile and convoluted in this nonlaminar region. This flame fluctuation behavior is reinforced in Figure 6, which shows $\mathrm{CH}$ chemiluminescence intensity fluctuations in the perturbed reaction zones of the flame using a collection volume that is just slightly larger than a laminar reaction zone thickness. Two $\mathrm{CH}$ chemiluminescence images detailing additional observed turbulent flame behavior are shown in Figure 7. The image on the left, with no applied voltage, is a laminar flame with well-defined preheat and reaction zones. The image on the right is for the same flow condition subjected to a $+2.7 \mathrm{kV}$ applied pulsed voltage for $4 \mathrm{~ms}$ and this $\mathrm{CH}$ chemiluminescence image shows the effects of ionic wind $4 \mathrm{~ms}$ after the pulsed voltage has been shut off. The disturbance from the applied voltage has amplified an already present instability causing the flame to become locally turbulent. Compared to the image on the left, the image on the right shows an increase of the disturbance in the middle of the flame causing the reaction zone to move closer to the centerline and to the burner head. This increase in burning velocity leads to an increased consumption of premixed fuel and air causing an increase in $\mathrm{CH}$ chemiluminescence intensity in this region. This increase in relative chemiluminescence intensity maximizes at 16\%, 3 ms after the end of the applied voltage pulse. While it has been shown that $\mathrm{CH}$ chemiluminescence can be used as a flame front marker, quantitative measurements are difficult to obtain since it is a line-of-sight volume-average technique.
It is important to note that these effects seem to be localized. While the lower portions of the flame near the burner head show this increase in burning rates and chemiluminescence intensity, near the tip region of the flame it is highly strained in order to accommodate the turbulence originating at or near the burner head. This highly strained flame stretch approach local extinction. For the $3 \mathrm{kV}$ applied voltage condition, the $\mathrm{CH}$ chemiluminescence image in Figure 7 shows the reaction zones above the highly wrinkled region are almost entirely vertical indicating that the flame tip is approaching an open condition. This generally occurs in highly strained flames that are close to the extinction limits. This local extinction that can be seen in Figure 5 as the wrinkled turbulent structure is convected downstream causing extinction. In some situations, these strain rates are so high that a localized extinction is achieved, but burning occurs both up and downstream from this location. This is shown in Figure 5 for both 10 and $11 \mathrm{~ms}$ time delayed $\mathrm{CH}$ chemiluminescence intensity images. Figure 8 shows the $\mathrm{OH}$ chemiluminescence intensity image of the unperturbed flame and a plot of the temporal response of $\mathrm{OH}$ chemiluminescence intensity measured with a non-gated photomultiplier imaging the lower portion of the flame volume. The impulse behavior of the $\mathrm{OH}$ chemiluminescence intensity shows similarity to thermoacoustic instability.

By modifying air flow speed it is possible to further explore the convective process that determines the propagation of the pulsed voltage-current-induced perturbation of the flame. Figure 9 shows the behavior of three flames that differ only in the flow speed with the same equivalence ratio, applied voltage, and anode location. These results show that magnitude of the flame perturbation does not change significantly with the overall flow speed. However, the speed at which the flow disturbance moves downstream is dependent on the total flow speed. Using the 200 microsecond timegated chemiluminescence images it was determined that the disturbance moved at roughly the same speed as the gas flow speed for all three cases. These data also show that the pulsed voltage-current-induced combustion instability is initiated near the cathodic burner head and this induced instability is transported downstream by the gas flow.

These experimental results suggest that chemi-ion current induced body force, originating only near the cathodic burner head, is the dominant mechanism that controls this flame flow-field behavior. The observed flame flow perturbation becomes much more localized when the anode location is moved from above the flame tip to close to the cathode region. This anode-cathode configuration is responsible for creating a radially directed inward force at the base of the flame producing effects similar to those seen in swirlstabilized flames generating a hotter primary reaction zone due to enhanced fuel and air mixing inside a normally colder partially burned gas zone. These findings show results similar to the thermoacoustic instability [34] suggesting that creation of vortices near the base of the flame could lead to further instability. These effects are dependent on the current density, pulse width, and anode-cathode locations, and it appears to improve flame holding. 


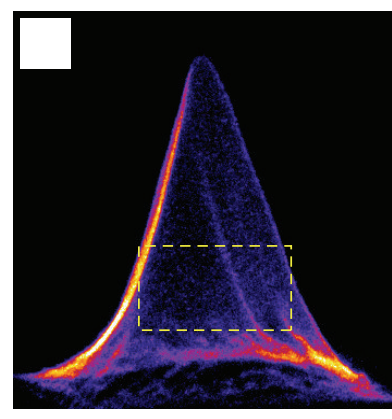

No voltage

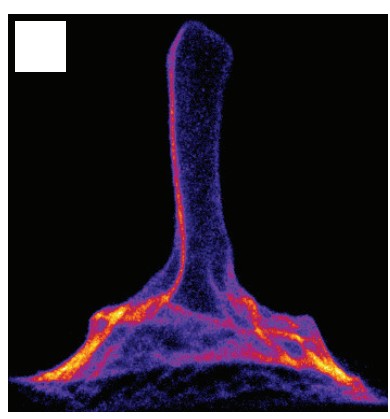

$3 \mathrm{kV}(4 \mathrm{~ms})$

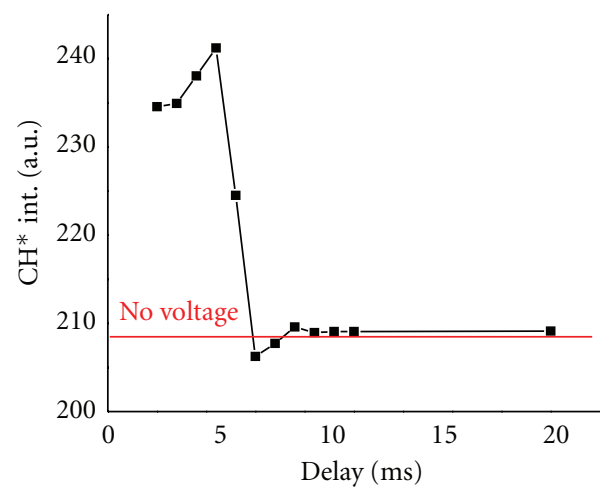

(c)

(b)

Figure 7: CH chemiluminescence images showing a comparison of flame structure for a $\Phi=1.1, v=1.58 \mathrm{~m} / \mathrm{s}$ flame with no voltage (left), $+2.7 \mathrm{kV}$ applied voltage, and the resultant $\mathrm{CH}$ chemiluminescence intensity plot (right). Note the local reduction in flame height and a $16 \%$ increase in $\mathrm{CH}$ chemiluminescence intensity due to disturbance in the middle of the flame. Image is rescaled to highlight the high intensity regions. Region of interest used for $\mathrm{CH}$ intensity plot is shown on the left.

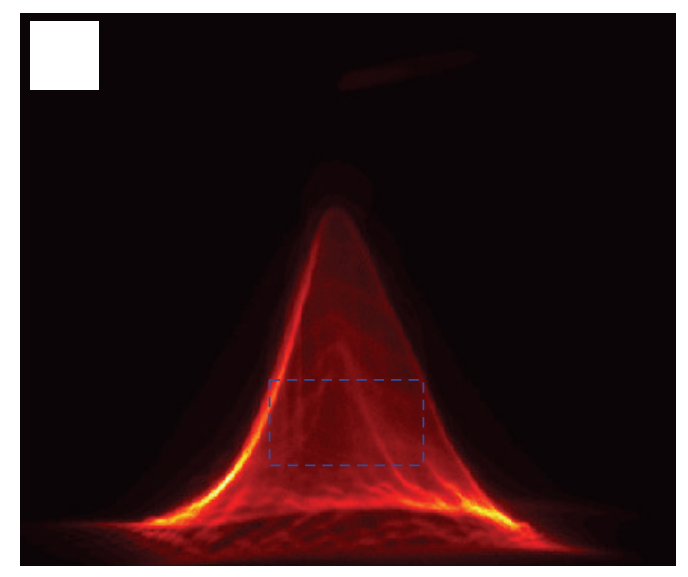

(a)

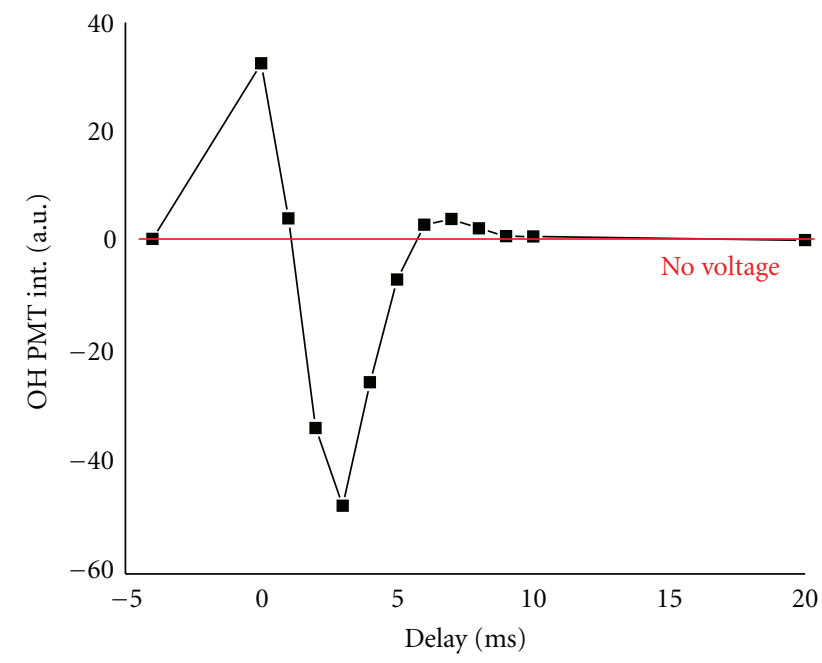

(b)

FIGURE 8: Plot of temporal response of OH chemiluminescence intensity. Impulse behavior, showing an initial increase in OH (A-X) emission intensity, exhibits similarities to thermoacoustic instability.

Assuming complete combustion for a premixed propane/air flame at stoichiometric condition, the estimated total chemical energy release for a flame with a total flow rate of $1.1 \mathrm{~m} / \mathrm{s}$ and a fuel flow rate of 0.913 standard liter per minute is about $1.4 \mathrm{~kW}$. The amount of electrical energy applied to these flames to produce a significant flame perturbation ranged from $0.4 \mathrm{~W}$ to $0.7 \mathrm{~W}$, which is less than $1 \%$ of the total chemical energy required to modify the combustion flow field. The small electrical input energy relative to the chemical energy output seem to produce a significant improvement in flame holding as noted by other groups $[1-3,5,6,9,35-38]$.

\section{Conclusion}

In conclusion, we have investigated the effect of millisecond wide pulsed applied voltage, below self-sustained break- down, for various pulse width and electrode locations on the structure of a premixed propane/air flame. Flame structures were visualized by phase-locked 2-D CH (A-X) chemiluminescence images, time-resolved volume-averaged $\mathrm{OH}$ (A-X) chemiluminescence, and simultaneously quantified with phase-locked spontaneous $\mathrm{N}_{2}$ Raman scattering for gas temperature measurement. These results indicate that there are specific limits on both the upper and the lower bounds of the voltage-current pulse width that control the response of the flame reaction zone structure. The experimentally determined low-frequency limit agrees with a limit imposed by the ion-neutral collisional kinetics, but experimentally determined high-frequency limits appear to be too low for the volumetric ionic wind to have any measurable effect on the flame. These findings have been verified by studying the effect of electrode location, specifically anode location. Through this study we have noted 


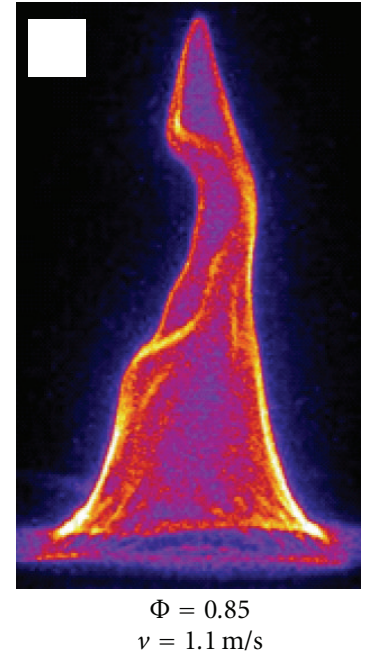

(a)

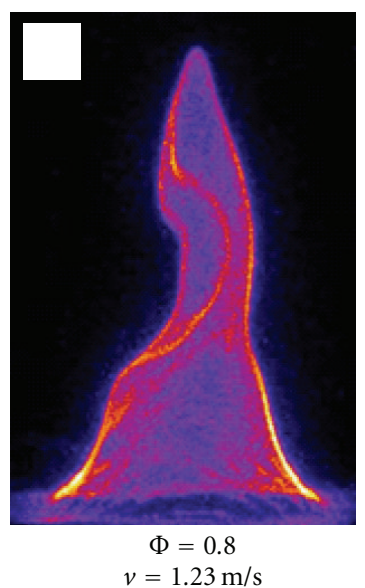

(b)

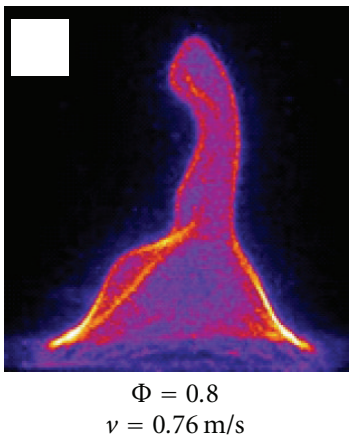

(c)

FIGURE 9: $\mathrm{CH}(\mathrm{A}-\mathrm{X})$ chemiluminescence showing flow speed-dependent propagation of the flame reaction zone structure modification with pulsed applied voltage. The speed at which the flame flow perturbation moves downstream is dependent on the total flow speed.

that the flame flow field response is a function of chemi-ion current amplitude and pulse width as well as the current conduction path through the flame reaction zone. The anode location-dependent result, along with the previously reported cathode location-dependent effects [21], suggests that a net momentum is imparted by the positive chemiion charge carriers to the neutral gas. It seems to create a radially applied body force normal to the net positive space-charge distribution at or near the cathode producing effects similar to a swirl-stabilized flame. Also, the effect of this body force seems to be very sensitive to the viscous damping and/or to the ratio of thermal velocity to the ionic wind-induced directed velocity change, as shown from the cathode [21] and anode location-dependent effects. These effects seem to improve flame-holding effect, and that could help with the lean flame blow out with only a small fractional amount of additional electrical energy input to the flame. Furthermore, chemi-ion current-induced body can cause a premixed laminar flame transition to a turbulent flame [16] which potentially can reduce NOx formation in a near-stoichiometric flame through enhance gas recirculation near the burner head $[8,39]$.

\section{Nomenclature}

$\alpha: \quad$ Calibration constant

$\mathbf{m}_{\mathbf{e}}, \mathbf{m}_{\mathbf{i}}$ : Mass of an electron, ion

$N$ : $\quad$ Number density of nitrogen

$\mathbf{n}_{\mathbf{e}}, \mathbf{n}_{\mathbf{i}}$ : Number density of an electron, ion

$\mathbf{T}_{\mathrm{e}}, \mathbf{T}_{\mathrm{i}}$ : Temperature of an electron, ion

$\mathbf{u}_{\mathbf{e}}, \mathbf{u}_{\mathbf{i}}$ : Velocity of an electron, ion

$\mathbf{v}_{\mathbf{e}}, \mathbf{v}_{\mathbf{i}}$ : Collision frequency of an electron, ion

$\tilde{\nu}_{k}$ : Raman shift frequency

$\tilde{\nu}_{0}: \quad$ Raman excitation frequency

$c_{o}$ : Speed of light in a vacuum
E: $\quad$ Strength of electric field

$e$ : Fundamental charge

$\mathbf{f}_{\mathrm{e}}, \mathbf{f}_{\mathrm{i}}$ : Volumetric force of an electron, ion

$h$ : Planck's constant

$I_{S}, I_{a S}:$ Signal intensity of Stokes-shifted, anti-Stokes-shifted light

$\mathbf{k}_{\mathrm{B}}$ : Boltzmann's constant.

\section{Acknowledgments}

This paper was supported by the Air Force Office of Scientific Research (AFOSR), Julian Tishkoff, technical monitor. All work was performed at Wright-Patterson Air Force Base.

\section{References}

[1] M. Kim, S. Ryu, S. Won, and S. Chung, "Electric fields effect on liftoff and blowoff of nonpremixed laminar jet flames in a coflow," Combustion and Flame, vol. 157, no. 1, pp. 17-24, 2010.

[2] C. Maupin and H. Harris, "Electrical perturbation of cellular premixed propane/air flames," Combustion and Flame, vol. 97, no. 3-4, pp. 435-439, 1994.

[3] A. Ata, J. Cowart, A. Vranos, and B. Cetegen, "Effects of direct current electric field on the blowoff characteristics of bluffbody stabilized conical premixed flames," Combustion Science \& Technology, vol. 177, no. 7, pp. 1291-1304, 2005.

[4] J. Fox and I. Mirchandani, "Influence of electric fields on burning velocity," Combustion and Flame, vol. 22, no. 2, pp. 267-268, 1974.

[5] A. Starikovsk, "Plasma supported combustion," Proceedings of the Combustion Institute, vol. 30, pp. 2405-2417, 2005.

[6] A. Fialkov, "Investigations on ions in flames," Progress in Energy and Combustion Science, vol. 23, no. 5-6, pp. 399-528, 1997.

[7] A. Sepp and K. Ulybyshev, "Experimental investigation of the emission characteristics of laminar diffusion flames in 
constant electric field of different polarity," High Temperature, vol. 35, no. 5, pp. 815-817, 1997.

[8] E. Vega, S. Shin, and K. Lee, "NO emission of oxygen-enriched $\mathrm{CH}_{4} / \mathrm{O}_{2} / \mathrm{N}_{2}$ premixed flames under electric field," Fuel, vol. 86, no. 4, pp. 512-519, 2007.

[9] A. Sakhrieh, G. Lins, F. Dinkelacker, T. Hammer, A. Leipertz, and D. Branston, "The influence of pressure on the control of premixed turbulent flames using an electric field," Combustion and Flame, vol. 143, no. 3, pp. 313-322, 2005.

[10] H. Jaggers and A. von Engel, "The effect of electric fields on the burning velocity of various flames," Combustion and Flame, vol. 16, no. 3, pp. 275-285, 1971.

[11] H. Jaggers, R. Bowser, and F. Weinberg, "The effect of electric fields on burning velocity," Combustion and Flame, vol. 19, no. 1, pp. 135-136, 1972.

[12] S. Abrukov, V. Afanas'ev, V. Borisov, and N. Medvedev, "Effect of an electric field on combustion in channels with insulated walls," Combustion, Explosion, and Shock Waves, vol. 17, no. 3, pp. 268-272, 1981.

[13] J. van den Boom, A. Konnov, A. Verhasselt, A. Kornilov, L. de Goey, and H. Nijmeijer, "The effect of a DC electric field on the laminar burning velocity of premixed methane/air flames," Proceedings of the Combustion Institute, vol. 32, pp. 1273-1244, 2009.

[14] A. Vincent-Randonnier, "Combustion enhancement and stabilization: principles of plasma assistence and diagnostics tools," in Handbook of Combustion, M. Lackner, F. Winter, and A. Agarwal, Eds., vol. 5, chapter 6, Wiley-VCH, Weinheim, Germany, 2010.

[15] V. Nori and J. Seitzman, "CH* chemiluminsecence modeling for combustion diagnostics," Proceedings of the Combustion Institute, vol. 32, pp. 895-903, 2009.

[16] S. Marcum and B. Ganguly, "Electric-field-induced flame speed modification," Combustion and Flame, vol. 143, no. 12, pp. 27-36, 2005.

[17] J. Lawton and F. Weinberg, "Maximum ion currents from flames and the maximum practical effects of applied electric fields," Proceedings of the Royal Society of London, vol. 277, pp. 468-497, 1964.

[18] J. Boeuf and L. Pitchford, "Electrohydrodynamic force and aerodynamic flow acceleration in surface dielectric barrier discharge," Journal of Applied Physics, vol. 97, no. 10, Article ID 103307, pp. 1-10, 2005.

[19] I. Glassman, Combustion, Academic Press, New York, NY, USA, 1996.

[20] J. Rodrigues, A. Agneray, X. Jaffrezic et al., "Evolution of charged species in propane/air flames: mass-spectrometric analysis and modelling," Plasma Sources Science and Technology, vol. 16, no. 1, article 021, pp. 161-172, 2007.

[21] D. Wisman, B. Ganguly, and S. Marcum, "Importance of electrode location on flames modified by low applied electric fields," in Proceedings of the 46th AIAA Aerospace Sciences Meeting and Exhibit, AIAA, Reno, Nev, USA, January 2008.

[22] C. Vagelopoulos and J. Frank, "An experimental and numerical study on the adequacy of $\mathrm{CH}$ as a flame marker in premixed methane flames," Proceedings of the Combustion Institute, vol. 30, pp. 241-249, 205.

[23] V. Nori and J. Seitzman, "Evaluation of chemiluminescence as a combustion diagnostic under varying operating conditions," in Proceedings of the 46th AIAA Aerospace Sciences Meeting and Exhibit, AIAA, Reno, Nev, USA, January 2008.

[24] B. Higgins, M. McQuay, F. Lacas, J. Rolon, N. Darabiha, and S. Candel, "Systematic measurements of $\mathrm{OH}$ chemiluminescence for fuel-lean, high-pressure, premixed, laminar flames," Fuel, vol. 80, no. 1, pp. 67-74, 2001.

[25] H. Najm, P. Paul, C. Mueller, and P. Wyckoff, "On the adequacy of certain experimental observables as measurements of flame burning rate," Combustion and Flame, vol. 113, no. 3, pp. 312-332, 1998.

[26] B. Ayoola, R. Balachandran, J. Frank, E. Mastorakos, and C. Kaminski, "Spatially resolved heat release rate measurements in turbulent premixed flames," Combustion and Flame, vol. 144, no. 1-2, pp. 1-16, 2006.

[27] C. Lawn, "Distributions of instantaneous heat release by the cross-correlation of chemiluminescent emissions," Combustion and Flame, vol. 123, no. 1-2, pp. 227-240, 2000.

[28] Y. Ikeda, J. Kojima, and H. Hashimoto, "Local chemiluminescence spectra measurements in a high-pressure laminar methane/air premixed flame," Proceedings of the Combustion Institute, vol. 29, pp. 1495-1501, 2002.

[29] Y. Ikeda, J. Kojima, T. Nakajima, F. Akamatsu, and M. Katsuki, "Measurement of the local flamefront structure of turbulent premixed flames by local chemiluminescence," Proceedings of the Combustion Institute, vol. 28, no. 1, pp. 343-350, 2000.

[30] J. Luque, J. Jeffries, G. Smith et al., " $\mathrm{CH}(\mathrm{A}-\mathrm{X})$ and $\mathrm{OH}(\mathrm{A}-\mathrm{X})$ optical emission in an axisymmetric laminar diffusion flame," Combustion and Flame, vol. 122, no. 1-2, pp. 172-175, 2000.

[31] A. Karpetis and A. Gomez, "Temperature measurements in spray flames by spontaneous Raman scattering," Optics Letters, vol. 21, no. 10, pp. 704-706, 1996.

[32] S. Lederman, "The use of laser Raman diagnostics in flow fields and combustion," Progress in Energy and Combustion Science, vol. 3, no. 1, pp. 1-34, 1977.

[33] A. Eckbreth, Laser Diagnostics for Combustion Temperature and Species, Abacus, Cambridge, UK, 1996.

[34] D. Durox, T. Schuller, and S. Candel, "Combustion dynamics of inverted conical flames," Proceedings of the Combustion Institute, vol. 30, pp. 1717-1724, 2005.

[35] Y. Matsui, "An experimental study on pyro-acoustic amplification of premixed laminar flames," Combustion and Flame, vol. 43, pp. 199-209, 1981.

[36] H. Calcote and R. Pease, "Electrical properties of flamesburner flames in longitudinal electric fields," Industrial and Engineering Chemistry, vol. 43, no. 12, pp. 2726-2731, 1951.

[37] H. Calcote and C. Berman, "Increased methane-air stability limits by a DC electric field," in Proceedings of the ASME Fossil Fuels Combustion Symposium, vol. 25, pp. 25-31, Houston, Tex,USA, 1989.

[38] C. Berman, R. Gill, H. Calcote, and T. Xiong, "Enhanced flame stability using electric fields," Tech. Rep. GRI-92-0518, Gas Research Institute, Chicago, Ill, USA, 1992.

[39] J. Schmidt, S. Kostka, A. Lynch, and B. Ganguly, "Simultaneous PIV and chemiluminescence visualization of millisecond pulsed voltage-current induced perturbations of a premixed propane/air flame," in Proceedings of the 49th AIAA Aerospace Sciences Meeting and Exhibit, Orlando, Fla, USA, January 2011. 

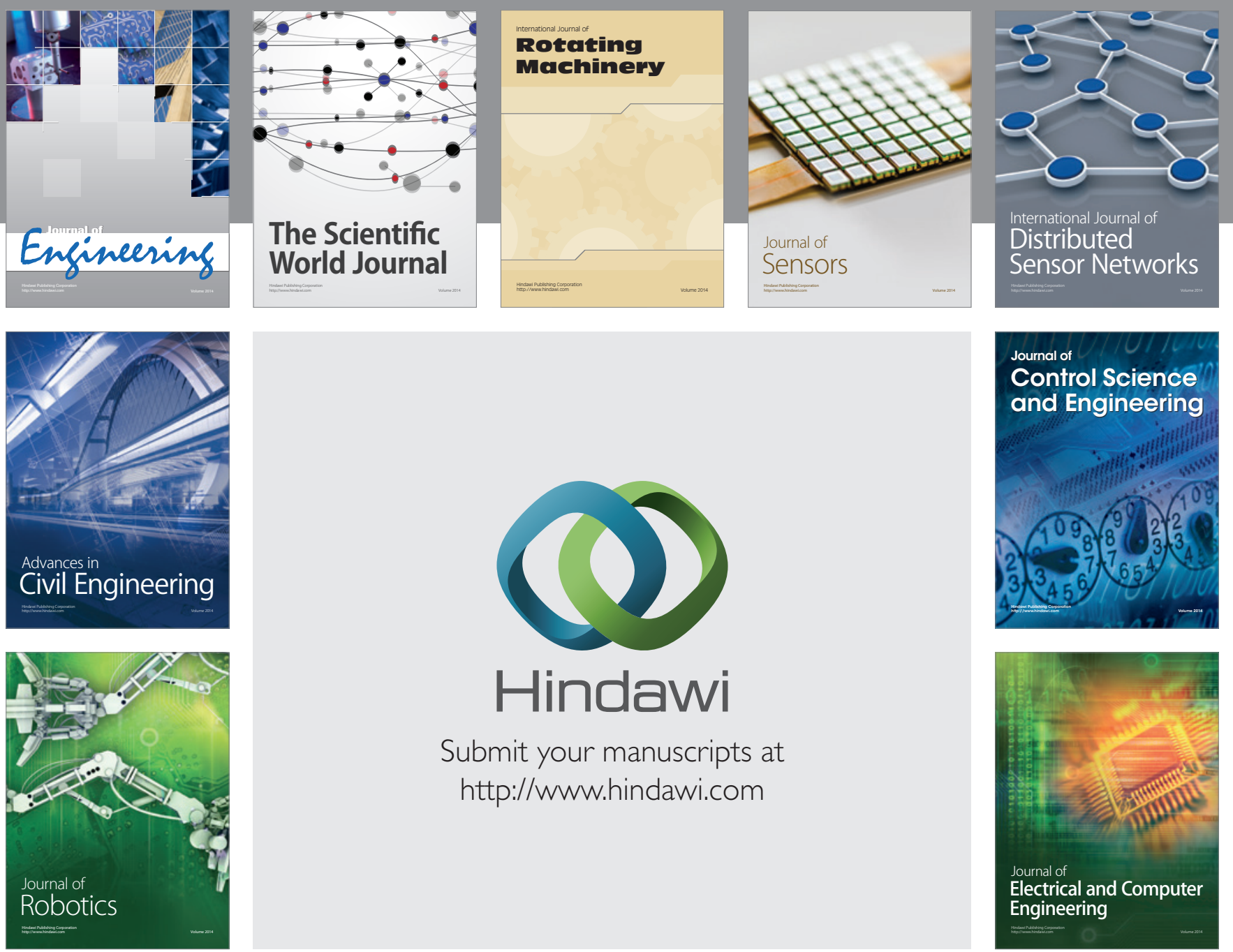

Submit your manuscripts at

http://www.hindawi.com
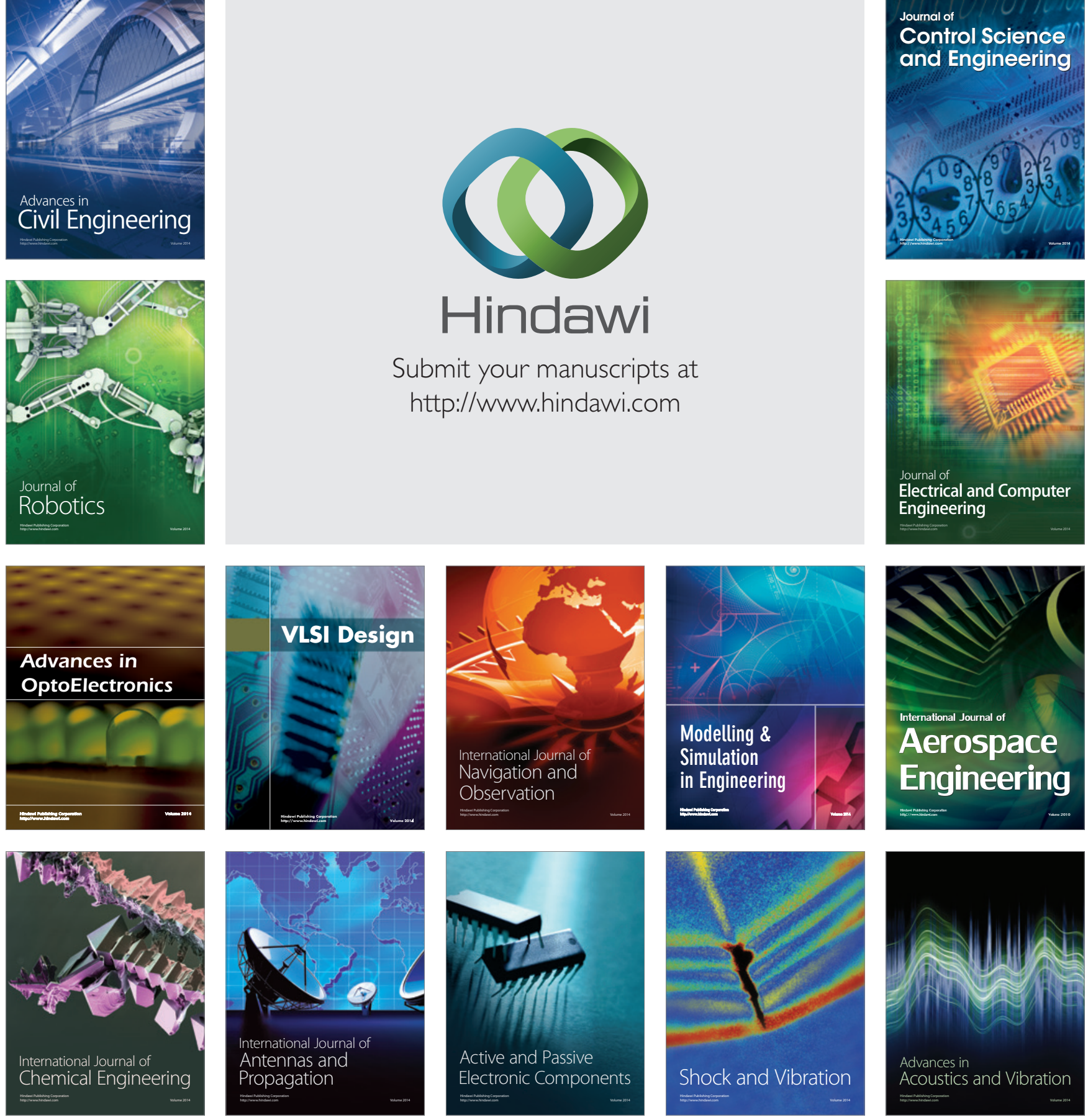